\title{
Recomendaciones para viajeros chilenos a la Copa Mundial de la FIFA 2014 en Brasil
}

\author{
Cecilia Perret y Thomas Weitzel, en representación del Comité de Infecciones \\ Emergentes de la Sociedad Chilena de Infectología*
}

\section{Recommendations for Chilean travelers to the FIFA World Cup 2014 in Brazil}

This article provides a checklist of precautions and vaccines for Chilean travelers attending the FIFA World Cup 2014 in Brazil. It aims to help physicians to prepare visitors of this mass gathering and summarizes useful hints to avoid infectious diseases considering the circumstances and availabilities in Chile.

Este artículo proporciona una serie de precauciones a observar y vacunas recomendadas para viajeros chilenos que asistirán a la Copa Mundial de Fútbol 2014 en Brasil. Su propósito es ayudar a los médicos a preparar a los visitantes a este masivo evento y resume las recomendaciones útiles para evitar enfermedades infecciosas, teniendo en consideración las circunstancias y disponibilidad en Chile.

$\mathrm{M}$ iles de viajeros de todas partes del mundo se congregarán en Brasil este año por motivos del Mundial de Futbol. Para que la experiencia de vivir esta Copa sea agradable existen recomendaciones para disminuir el riesgo de adquisición de enfermedades que se encuentran presentes en Brasil o que pueden ser trasmitidas por extranjeros provenientes de países con endemias diferentes de enfermedades infecciosas. El presente artículo resume las recomendaciones básicas para la prevención de enfermedades infecciosas en las diferentes partes de Brasil.

La selección chilena comienza su participación en la Copa en la ciudad de Cuiabá jugando también en Río de Janeiro y Sao Paulo. Si pasan la fase de grupos pueden jugar también en Belo Horizonte, Fortaleza y Salvador (Figura 1).

En todas las regiones en Brasil existe el riesgo de enfermedades trasmitidas por agua y alimentos como diarrea del viajero, fiebre tifoidea, hepatitis A y varios otros. Las medidas de prevención están basadas en el consumo de alimentos de bajo riesgo y el beber agua segura. Estas medidas consisten en:

$\checkmark$ Consumir todos los alimentos cocidos, recién preparados y calientes.

$\checkmark$ Consumir fruta que se pueda lavar con agua potable y pelar.

$\checkmark$ Beber sólo agua/bebidas embotelladas o hervidas.

$\checkmark$ Evitar el uso de hielo.

$\checkmark$ Consumir productos lácteos preparados industrialmente.

$\checkmark$ Evitar el consumo de verduras, carnes, pescados y mariscos crudos.

$\checkmark$ Evitar el consumo de jugos de frutas frescas o de caña preparados en la vía pública y en lugares que no cumplan estándares sanitarios adecuados.

$\checkmark$ Lavar sus manos con agua y jabón o alcohol gel previo al consumo de alimentos.

En caso de diarrea se recomienda aumentar la hidratación y se pueden usar medicamentos que podrían aliviar los síntomas y reducir la duración:

$\checkmark$ Antimicrobiano: su uso puede acortar la duración e intensidad de la diarrea, especialmente si es de alta frecuencia o tiene características de etiología bacteriana (presencia de fiebre, diarrea disentérica). Son recomendados: ciprofloxacina (500 mg cada $12 \mathrm{~h}$ ) o azitromicina ( $500 \mathrm{mg}$ al día), durante 3 días.

$\checkmark$ Loperamida: inicialmente $4 \mathrm{mg}$, después $2 \mathrm{mg}$ después de cada evacuación (máximo $16 \mathrm{mg}$ al día), duración según evolución, en general 2 a 3 días; en niños se puede utilizar a partir de los 3 años de edad, en dosis de $0,25 \mathrm{mg} / \mathrm{kg} /$ día distribuidos en tres a cuatro dosis.

En Brasil hay varias infecciones transmitidas por mosquitos. Existe la probabilidad de trasmisión de dengue en todo Brasil incluyendo ciudades grandes. Malaria ocurre en zonas selváticas en el nor-oeste de Brasil. La única ciudad sede del Mundial en cuyos alrededores existe riesgo de trasmisión de malaria es Manaos, en la cual no jugaría la selección chilena. Fiebre amarilla es endémica en el interior de Brasil, ciudades sede del Mundial afectadas son Cuiabá, Manaos, Brasilia, Bello Horizonte y Porto Alegre.

Se recomienda para evitar la trasmisión de enfermedades por artrópodos:

$\checkmark$ Uso de repelente para la piel, que contenga DEET (dietil-meta-toluamida) en concentraciones $>25 \%$. En
Pontificia Universidad Católica de Chile.

Escuela de Medicina. Santiago, Chile (CP).

Clínica Alemana, Universidad del Desarrollo. Santiago, Chile Programa Medicina del Viajero (TW)

*Miembros de Comité de Infecciones Emergentes Gerardo Acosta-Jamett Ximena Aguilera Jeannette Dabanch Alberto Fica

Juan C. Hormazabal

Leonor Jofré Javier López Verónica Solari Marisa Torres

Recibido: 19 de marzo de 2014 Aceptado: 28 de marzo de 2014

Correspondencia a: Thomas Weitzel thomas.weitzel@gmail.com 


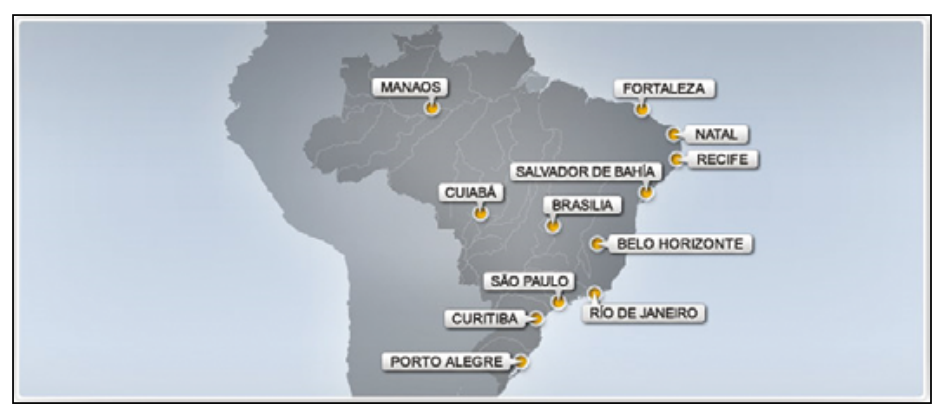

Figura 1. Ciudades sedes del Mundial de Fútbol 2014, Brasil. Fuente: FIFA (http:// es.fifa.com/worldcup/destination).

Chile, sólo el producto Everglades ${ }^{\circledR}$ cumple con esta concentración. Debe aplicarse en la piel expuesta cada $6 \mathrm{~h}$ durante el día comenzando desde la mañana. En zonas donde además existe riesgo de malaria su uso debe ser también desde el atardecer. Poner sobre el bloqueador solar o cualquier otro producto.

$\checkmark$ Zonas de malaria: el riesgo es bajo en área urbana de Manaos, pero viajeros a zonas selváticas (ej. en las cercanías de Manaos) deben evaluar la necesidad de quimioprofilaxis. La profilaxis de elección es atovaquona/proguanil (Malarone $\left.{ }^{\circledR}\right), 1$ comp al día desde un día antes de la exposición hasta siete días después de salir de la zona por tener menos efectos secundarios. Alternativas igualmente eficaces: doxiciclina (100 $\mathrm{mg}$ al día desde un día antes hasta 30 días después) o mefloquina (250 $\mathrm{mg}$ a la semana desde una semana antes hasta 4 semanas después). Cuadros febriles en asociación con viaje a zona de malaria necesitan evaluación médica para excluir malaria.

Los viajes están asociados con un riesgo aumentado de enfermedades de transmisión sexual y por inoculación directa como infección por VIH, hepatitis B, entre otros. Por eso se recomienda:

$\checkmark$ Uso de condón en caso de relaciones sexuales con parejas ocasionales.

$\checkmark$ Evitar procedimientos como tatuajes y piercing.

\section{Otras recomendaciones:}

Prevención de larva cutánea migrante y tungiasis. Estos parásitos se encuentran en la arena de playas contaminadas por deposiciones de perros.

$\checkmark$ Caminar en la arena con calzado.

$\checkmark$ Tomar el sol en toalla grande o reposera.

\section{Dermatitis por chinches:}

$\checkmark$ Inspeccionar las habitaciones en búsqueda de chinches o sus deposiciones en camas, colchones o sábanas.

$\checkmark$ Mantener las maletas cerradas y en alto, no sobre el suelo.

$\checkmark$ No dejar artículos o ropas en el suelo.

\section{Vacunas}

\section{$\checkmark$ Hepatitis A}

- Recomendación: para todos los viajeros sin antecedentes de hepatitis A o vacunación.

- Dosificación: 1 dosis antes del viaje-2ª dosis 6 a 12 meses después.

\section{Hepatitis B}

- Recomendación: Aquellos con posibilidad de tener sexo ocasional o procedimientos como piercing o tatuajes. Dosificación: 2 dosis (0-4 semanas) antes del viaje, $3^{\text {a }}$ dosis en 6-12 meses. Existe esquema acelerado (0-7-21 días) con $4^{\mathrm{a}}$ dosis al año.

\section{$\checkmark$ Hepatitis A+B (vacuna combinada)}

- Recomendación: ver arriba. Ofrecer o todos que necesitan vacuna hepatitis A y que presentan $>4$ semanas antes del viaje.

- Dosificación: lo mismo que para hepatitis B.

\section{$\checkmark$ Influenza}

- Recomendación: todos.

- Dosificación: 1 dosis.

\section{$\checkmark$ Tétanos}

- Recomendación: todos sin refuerzo de vacuna en los últimos 10 años.

- Dosificación: 1 dosis en forma dT o dTpa (que incluye componente pertussis acelular).

- En Chile los nacidos antes de 1975 no cuentan con vacunación primaria de tétanos por lo que al menos dos dosis debería recibir antes del viaje separadas por 1 mes; la $3^{\circ}$ dosis en 6 meses.

\section{$\checkmark$ Fiebre amarilla}

- Recomendación: viajeros a zonas endémicas (Cuiabá, Manaos, Porto Alegre, Brasilia, Belo Horizonte).

- Dosificación: 1 dosis.

- Contraindicaciones: inmunosupresión, anafilaxia al huevo o a la vacuna en dosis previas; debe aplicarse con precaución en edad $>60$ años y embarazo. En estos casos la indicación debe ser por especialista.

\section{Sarampión}

- Recomendación: ministerial a todos los nacidos entre 1971 y 1981 en Chile. Debe administrarse vacuna tresvírica.

- Dosificación: 1 dosis.

- Gratuita para los viajeros nacidos entre las fechas mencionadas.

\section{Fiebre tifoidea}

- Recomendación: viajeros que no pueden cumplir con recomendaciones para consumo de alimentos y agua segura, que se quedan por tiempo prolongado especialmente en zonas rurales o que desean una protección óptima.

- Dosificación: 1 dosis de vacuna inyectable o 3 dosis (0-2-4 días) de vacuna oral.

\section{$\checkmark$ Meningococo}

- Recomendación: viajeros que desean una protección óptima.

- Dosificación: 1 dosis (vacuna conjugada quadrivalente).

\section{$\checkmark$ Rabia}

- Recomendación: viajeros que se quedan por un tiempo prolongado ( $>1$ mes) especialmente en zonas rurales.

- Dosificación: 3 dosis antes del viaje (0-7-28 días). 